\title{
Microbiome of Infected Cysts, Feces and Saliva in Patients with Autosomal Dominant Polycystic Kidney Disease: Case Reports
}

\section{Tatsuya Suwabe}

Toranomon Hospital: Toranomon Byoin https://orcid.org/0000-0003-0825-2512

Hidetoshi Morita

Okayama University: Okayama Daigaku

Anushka Khasnobish

Okayama University: Okayama Daigaku

Hideki Araoka

Toranomon Hospital: Toranomon Byoin

Junichi Hoshino ( $\nabla$ jhoshinoind@gmail.com )

Department of Nephrology, Toranomon Hospital

\section{Case report}

Keywords: ADPKD, cyst infection, infected cyst, polycystic kidney disease

Posted Date: June 3rd, 2021

DOI: https://doi.org/10.21203/rs.3.rs-566913/v1

License: (c) (1) This work is licensed under a Creative Commons Attribution 4.0 International License. Read Full License 


\section{Abstract}

Background: Cyst infection is a frequent and serious complication of autosomal dominant polycystic kidney disease (ADPKD). It is often difficult to treat and can be fatal, but much is still unknown about this type of infection. Hematogenous spread via bacterial translocation in the intestine is considered to be the main cause, so intestinal flora may be involved. However, the exact role of the intestinal flora in cyst infection in ADPKD is unknown.

Case presentation: We report a 66-year-old woman and a 56-year-old man with ADPKD who had severe hepatic cyst infection. We analyzed the microbiome of infected cyst content, feces, and saliva in these two patients. The microbiome of patient 1 showed various bacteria in an infected cyst, whereas that of patient 2 showed only one bacterium. In both patients, the composition of the microbiome of the cyst content was quite different from those of feces and saliva, and the main bacteria in the infected cyst content represented a small proportion of those in feces and saliva.

Conclusions: Cyst infection in ADPKD can be caused by a single bacterium or multiple bacteria, and cyst content culture or blood culture may identify only some of the causative bacteria. The association between bacteria in cysts and those in feces or saliva remains uncertain, and further research on this topic is needed.

\section{Introduction}

Autosomal dominant polycystic kidney disease (ADPKD) is a common inherited disease [1], and cyst infection is a frequent and serious complication. Studies estimated that $30-50 \%$ of patients with ADPKD experience some form of kidney infection during their lifetime [2, 3], although cyst infection leading to hospitalization is much less frequent, occurring in approximately $9 \%$ of patients [4]. These infections sometimes become resistant to treatment and can be fatal, even when appropriate antibiotics are administered [4-6]. However, much is still unknown about cyst infection in ADPKD. The most common causative bacteria were reported to be enterobacteria $[4,5,7]$. Previously, we reported that cyst infection due to retrograde infection is rare and that the main cause of cyst infection is considered to be hematogenous spread via bacterial translocation in the intestine. Therefore, the intestinal flora is considered important for cyst infection, and it was found to play important roles in many kind of diseases [8]; however, its role in cyst infection in ADPKD is unknown.

In this article, we present the analysis of the microbiome of infected cysts, feces, and saliva in two patients with ADPKD. As far as we know, this is the first report on the microbiome in patients with cyst infection in ADPKD.

\section{Case Presentation}

\section{Case 1}


This patient was a 66-year-old Japanese woman with ADPKD who had been on dialysis for 14 years. She had undergone renal transcatheter arterial embolization (TAE) 7 years previously and had complete anuria. She developed left flank pain and fever and received an oral antibiotic (cefcapene pivoxil hydrochloride hydrate, $200 \mathrm{mg} /$ day). Her symptoms improved temporarily, but then they recurred, and 7 days later she was referred to our hospital. This was her first episode of cyst infection. At admission, her body temperature was $38.0^{\circ} \mathrm{C}$ and she had mild left flank pain. Her serum C-reactive protein level was $14.1 \mathrm{mg} / \mathrm{dL}$, and her white blood cell count, $6,200 / \mu \mathrm{L}$. Her blood culture test was negative.

\section{Imaging examinations}

Abdominal computed tomography (CT) was performed, as reported previously [9, 10]. Magnetic resonance tomography (MRI) was also performed to obtain transverse and sagittal T1-weighted images (T1WI), T2-weighted images (T2WI), and diffusion-weighted images (DWI), as reported previously [9, 10]. We diagnosed an infected hepatic cyst according to our diagnostic criteria $[9,10]$ (Supplementary File 1). The cyst showed intracystic fluid-fluid level and high intensity on the MRI DWI (Figure 1).

\section{Hospital treatment}

We administered an intravenous antibiotic (cefmetazole sodium, $1 \mathrm{~g} /$ day). However, because of the continued fever and large size of the infected renal cyst (diameter: $6 \mathrm{~cm}$ ), we decided to drain the cyst. The cyst content was dark, but the cyst content culture test result was negative. We also obtained samples of feces and saliva and compared her microbiome with that of the cyst content. After cyst drainage, her symptoms improved gradually, and she was discharged from the hospital.

\section{Microbial characterization}

We identified 106 genera and 11 phyla of bacteria and archaea in the microbiomes of the cyst content, feces, and saliva of the patient (Additional File 2). The top 10 most abundant genera and phyla in the infected cyst content are shown in Figure 2. In the cyst content, the prevalence of Clostridiaceae; $g$ was the highest (15\%), followed by Blautia (13\%) and Enterobacteriaceae (11.4\%). However, the proportions of the 10 most abundant genera and phyla in the cyst content were not as high in feces and saliva, although Streptococcus represented $25 \%$ of the genera in saliva (Figure 2). The V3-V4 regions of $16 \mathrm{~S}$ ribosomal RNA gene sequence of T1 have been deposited in GenBank/DDBJ/EMBL under accession number SAMD00291257.

\section{Case 2}

This patient was a 56-year-old Japanese man with ADPKD who had been on dialysis for 15 years. He had undergone renal TAE 6 years previously and had complete anuria. He was transferred to our hospital from other hospital, where he had been hospitalized for 2 months because of a refractory hepatic cyst infection. At that hospital, he had received an oral antibiotic (moxifloxacin hydrochloride, $400 \mathrm{mg} /$ day) and an intravenous one (panipenem/betamipron, $0.5 \mathrm{~g} /$ day) for a total of 2 months. At admission to our hospital, his body temperature was $37.0^{\circ} \mathrm{C}$ and he had a dull pain throughout the abdomen. His serum C- 
reactive protein level was $17.1 \mathrm{mg} / \mathrm{dL}$, and his white blood cell count, 8,900 / $\mu \mathrm{L}$. He had a history of one cyst infection 15 months previously.

\section{Imaging examinations}

Abdominal CT and MRI were performed, as reported previously $[9,10]$. We diagnosed an infected hepatic cyst according to our diagnostic criteria $[9,10]$ (Additional File 1). MRI (DWI) showed high intensity in the cyst, and MRI (T1 weighted image and T2 weighted image) and CT showed cyst wall thickening (Figure 3).

\section{Hospital treatment}

At our hospital, we initiated intravenous antibiotic administration (cefmetazole sodium, $1 \mathrm{~g} / \mathrm{day}$ ), but the patient's symptoms worsened, so we switched to intravenous administration of meropenem, 0.5 $\mathrm{g} /$ day. However, the symptoms still did not improve. Therefore, we drained the cyst on day 16 after transfer to our hospital. The cyst content was dark, and the cyst content culture test identified Escherichia coli. As in Case 1, we also obtained samples of feces and saliva for analysis. After cyst drainage, his symptoms improved gradually, and he was discharged from the hospital.

\section{Microbial characterization}

We identified 106 genera and 11 phyla of bacteria and archaea in the microbiomes of the cyst content, feces, and saliva of the patient (Additional File 3). The top 10 most abundant genera and phyla in the infected cyst content are shown in Figure 4. In the cyst content, the prevalence of Proteobacteria $f$ was the highest (89.4\%), followed by Agrobacterium (3.6\%) and Ruminococcus (0.9\%). In the feces the most common of these 10 most abundant genus or phyla were Enterococcus (46.2\%), followed by Lactobacillus (32.3\%), and Firmicutes (18.3\%); in the saliva, the percentage of Lactobacillus was 30.5\%; of Firmicutes, 29.9\%; and of Staphylococcus was 25.8\% (Figure 4). The V3-V4 regions of $16 \mathrm{~S}$ ribosomal RNA gene sequence of T2 have been deposited in GenBank/DDBJ/EMBL under accession number SAMD00291258.

\section{Discussion}

We present two different cases of patients with ADPKD and hepatic cyst infection. The microbiome of the infected cyst in Case 1 revealed various bacteria, even though this was the patient's first episode of a cyst infection. In contrast, the microbiome of the infected cyst in Case 2 revealed a single bacterium, even though the infection had been present for two months.

The finding in Case 1 suggests that cyst infection can be caused by multiple bacteria simultaneously, which is consistent with our previous study on the causative bacteria found in cultures of the cyst content and blood from patients with cyst infection [5]. In that study, we reported that, in some patients, multiple bacteria were cultured in blood or cyst content, and in about half of the patients with positive results for both blood and cyst content culture tests the causative bacteria were not the same in the blood and cyst 
content cultures. Our current study showed that a much greater variety of bacteria can be present simultaneously in the same infected cyst than we found in our previous study. Taken together, our findings suggest that bacteria cultured in blood or cyst content represent only some of the bacteria causing the infection. In fact, the sensitivity of a bacterial culture test may be relatively low for several reasons, such as use of an inappropriate culture medium that does not allow some bacteria to grow. If physicians encounter patients with a cyst infection that is resistant to antibiotic therapy, we recommend that they consider that bacteria cultured in blood or cyst content may represent only some of the causative bacteria and that they try changing the antibiotic strategy to target other kinds of bacteria aside from the cultured bacteria.

In contrast, our findings in Case 2 suggest that a cyst infection can also be caused by a single type of bacterium. The cyst culture test revealed $E$ coli, which was sensitive to cefmetazole and meropenem. However, antibiotic therapy with cefmetazole or meropenem was ineffective in this patient. This antibiotic resistance might have been due to poor penetration of these antibiotics into the cyst because both cefmetazole and meropenem are water-soluble antibiotics. This suggestion is supported by our previous finding that penetration of meropenem into cysts is poor [11].

Interestingly, in both cases the composition of the cyst content microbiome was quite different from that of feces or saliva. In addition, the proportion of the main genera and phyla in the cyst content was much lower than that in feces and saliva. These results might be inconsistent with our hypothesis that bacterial translocation is the main cause of cyst infection. We had expected that the causative bacteria of the cyst infection would be the major bacteria in the intestine. However, our finding that the causative bacteria were not highly prevalent in feces and saliva indicates that bacterial mass may not be important for bacterial translocation. This is the first report on the microbiome in patients with cyst infection in ADPKD, however this is a report of just two cases. The association between bacteria in cysts and those in feces and saliva remains uncertain, and further research on this topic is needed.

In conclusion, we present two cases of cyst infection in ADPKD in which the microbiome of the cyst content was quite different. Cyst infection in ADPKD can be caused by a single bacterium and by multiple bacteria. The composition of the microbiome of cyst content can be quite different from that of feces and saliva. More research is needed on this topic.

\section{Abbreviations}

ADPKD: Autosomal dominant polycystic kidney disease

TAE: transcatheter arterial embolization

CT: computed tomography

MRI: Magnetic resonance tomography

T1Wl: T1-weighted images 
T2Wl: T2-weighted images

DWI: diffusion-weighted images

\section{Declarations}

\section{Ethics approval and consent to participate}

The study was approved by the Institutional review board of Toranomon Hospital.

\section{Consent for publication}

Written consent to publish this information was obtained from study participants. The written consent to publish consent form is available for review under reasonable request.

\section{Competing interests}

The authors state that they have no Conflict of Interest (COI).

\section{Availability of data and materials}

All data generated or analyzed during this study are included in this published article.

\section{Funding}

This work was supported by Grants-in-Aid for Scientific Research from Japan Society for the Promotion of Science (JSPS KAKENHI Grant number JP18K08227 and JP19K17758). This study was also supported in part by a Grant-in-Aid for Progressive Renal Disease Research from the Ministry of Health, Labour and Welfare of Japan and by Okinaka Memorial Institute for Medical Research, Toranomon Hospital.

\section{Contributions}

TS, HA and JH collected and interpreted the clinical data and drafted the article. HM and AK performed microbiome analysis. All authors approved the final version to be published.

\section{Acknowledgements}

This manuscript was checked for language content by a native English-speaking medical editor at Yamada Translation Bureau, Inc. (Tokyo, Japan).

\section{References}

1. Torres VE: Polycystic kidney disase autosomal-dominant and recessive forms. Philadelphia: Lippincott Williams \& Wilkins; 2001. 
2. Gardner KD, Jr., Evan AP: Cystic kidneys: an enigma evolves. Am J Kidney Dis 1984, 3(6):403-413.

3. Schwab SJ, Bander SJ, Klahr S: Renal infection in autosomal dominant polycystic kidney disease. The American journal of medicine 1987, 82(4):714-718.

4. Sallee M, Rafat C, Zahar JR, Paulmier B, Grunfeld JP, Knebelmann B, Fakhouri F: Cyst infections in patients with autosomal dominant polycystic kidney disease. Clin J Am Soc Nephrol 2009, 4(7):1183-1189.

5. Suwabe T, Araoka H, Ubara Y, Kikuchi K, Hazue R, Mise K, Hamanoue S, Ueno T, Sumida K, Hayami N et al: Cyst infection in autosomal dominant polycystic kidney disease: causative microorganisms and susceptibility to lipid-soluble antibiotics. Eur J Clin Microbiol Infect Dis 2015, 34(7):1369-1379.

6. Suwabe T, Ubara Y, Higa Y, Nakanishi S, Sogawa Y, Nomura K, Nishimura H, Hoshino J, Sawa N, Katori $\mathrm{H}$ et al: Infected hepatic and renal cysts: differential impact on outcome in autosomal dominant polycystic kidney disease. Nephron Clinical practice 2009, 112(3):c157-163.

7. Jouret F, Lhommel R, Beguin C, Devuyst O, Pirson Y, Hassoun Z, Kanaan N: Positron-emission computed tomography in cyst infection diagnosis in patients with autosomal dominant polycystic kidney disease. Clinical journal of the American Society of Nephrology : CJASN 2011, 6(7):16441650.

8. Sebastian Domingo JJ, Sanchez Sanchez C: From the intestinal flora to the microbiome. Rev Esp Enferm Dig 2018, 110(1):51-56.

9. Suwabe T, Ubara Y, Sumida K, Hayami N, Hiramatsu R, Yamanouchi M, Hasegawa E, Hoshino J, Sawa N, Saitoh S et al: Clinical features of cyst infection and hemorrhage in ADPKD: new diagnostic criteria. Clin Exp Nephrol 2012, 16(6):892-902.

10. Suwabe T, Ubara Y, Ueno T, Hayami N, Hoshino J, Imafuku A, Kawada M, Hiramatsu R, Hasegawa E, Sawa $\mathrm{N}$ et al: Intracystic magnetic resonance imaging in patients with autosomal dominant polycystic kidney disease: features of severe cyst infection in a case-control study. BMC Nephrol 2016, 17(1):170.

11. Hamanoue S, Suwabe T, Ubara Y, Kikuchi K, Hazue R, Mise K, Ueno T, Takaichi K, Matsumoto K, Morita K: Cyst infection in autosomal dominant polycystic kidney disease: penetration of meropenem into infected cysts. BMC Nephro/ 2018, 19(1):272.

\section{Figures}




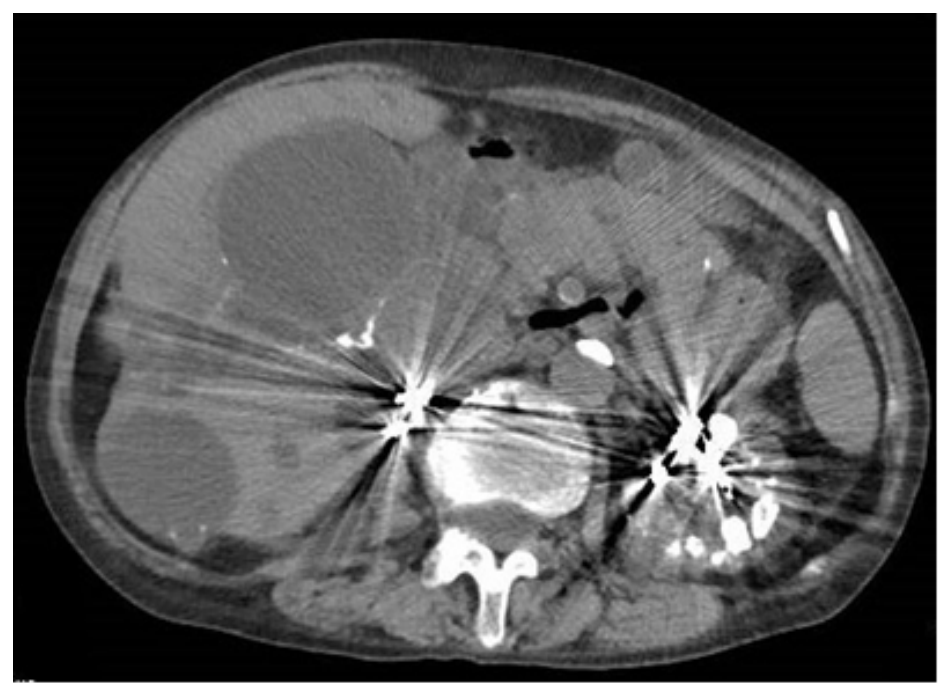

(CT)

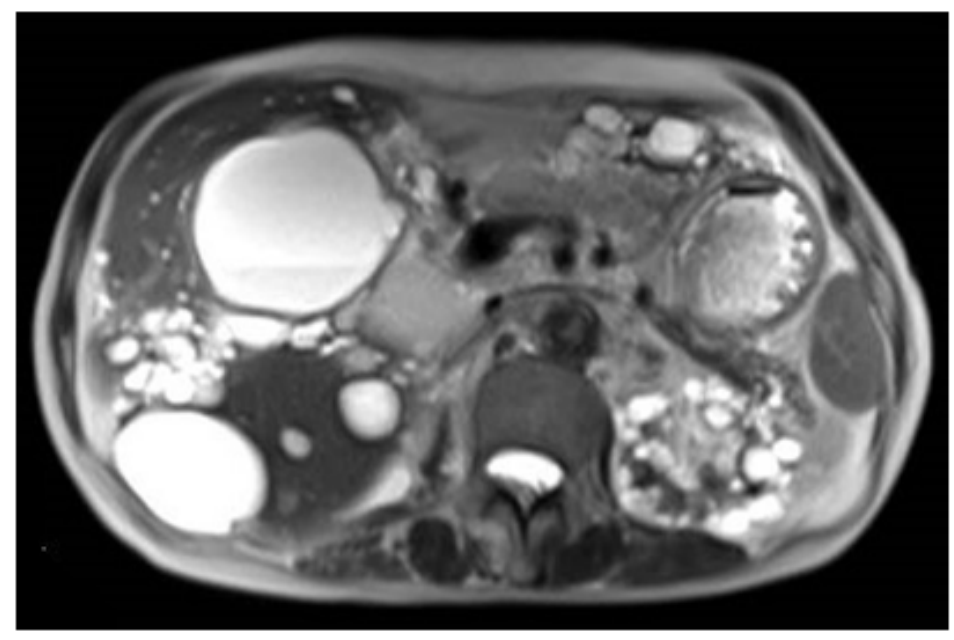

(MRI-T2WI)

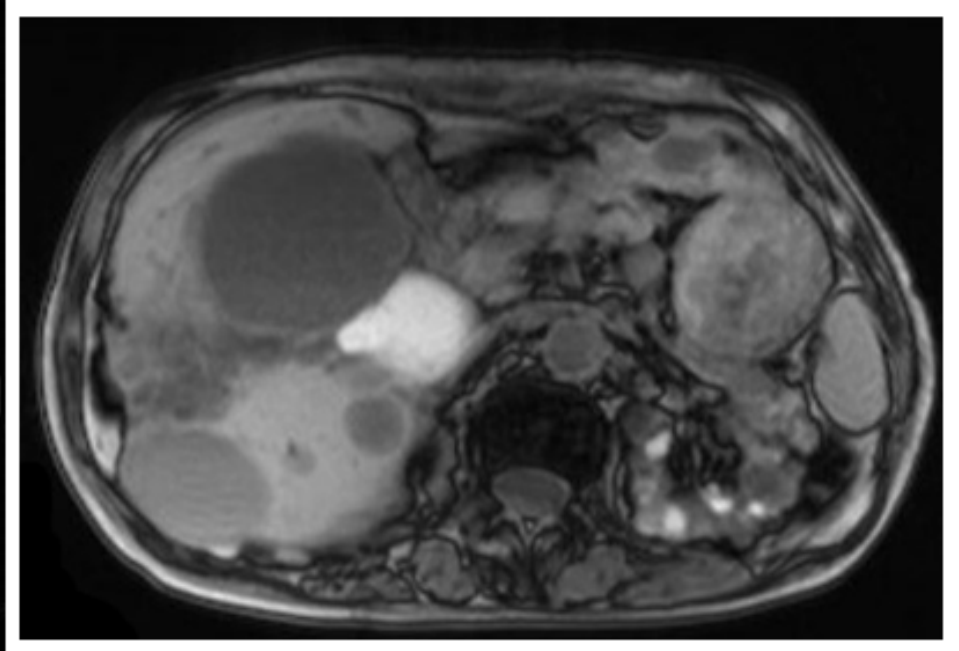

(MRI-T1WI)

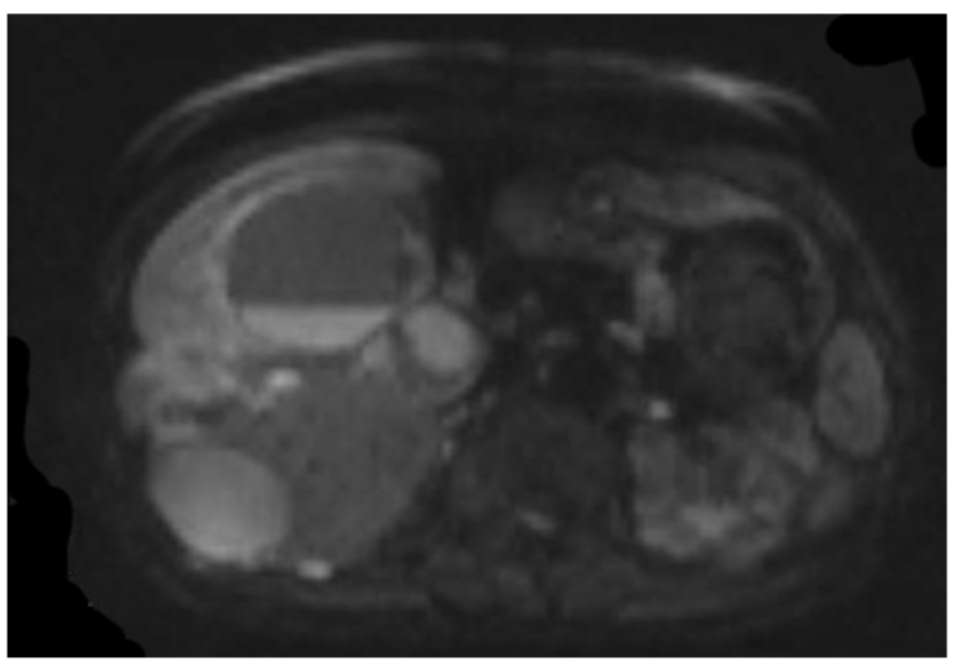

(MRI-DWI)

\section{Figure 1}

CT and MRI findings (T1WI, T2WI, and DWI) in Case 1. The infected hepatic cyst shows iso-density with normal cyst on CT and iso-intensity with normal cysts on qWI and T2WI. It showed intracystic fluid-fluid level and high intensity on DWI. 
25.00

20.00

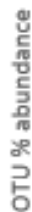

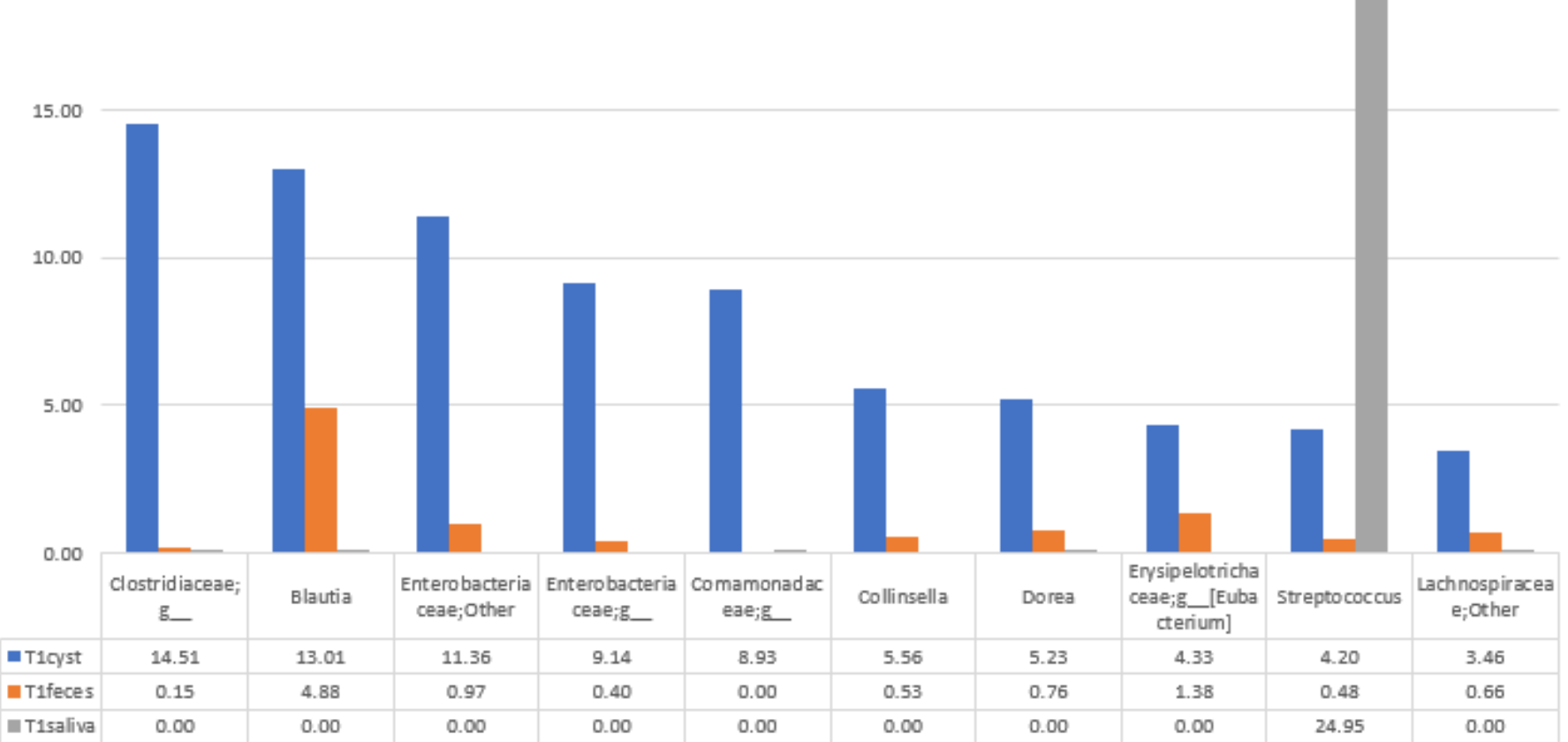

Figure 2

Top 10 most abundant genera in infected cyst content of Case 1 is presented compared to other catergories. 


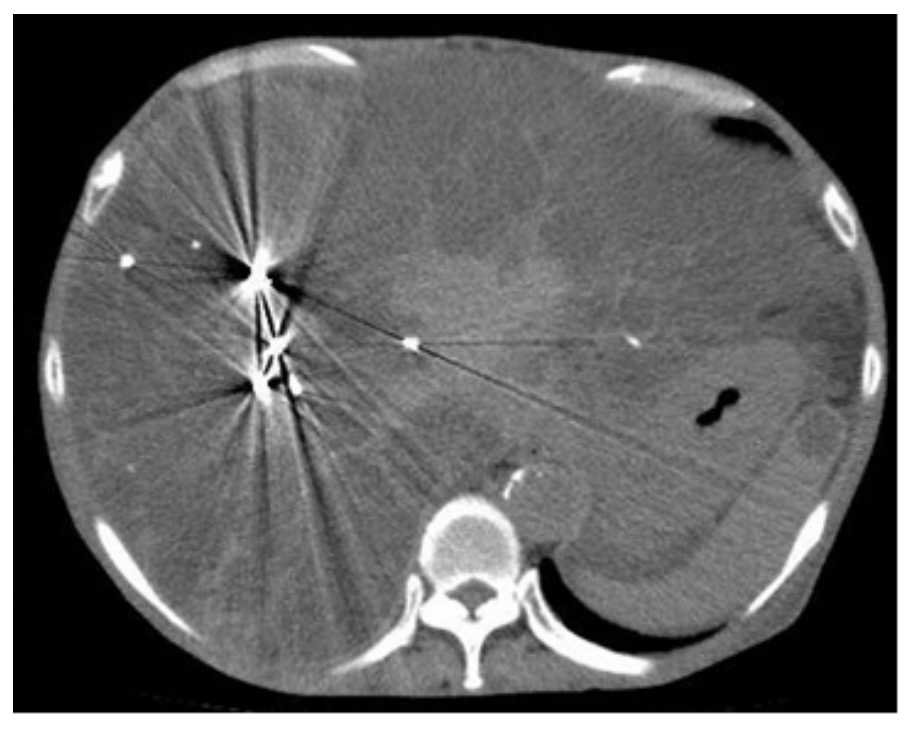

(CT)

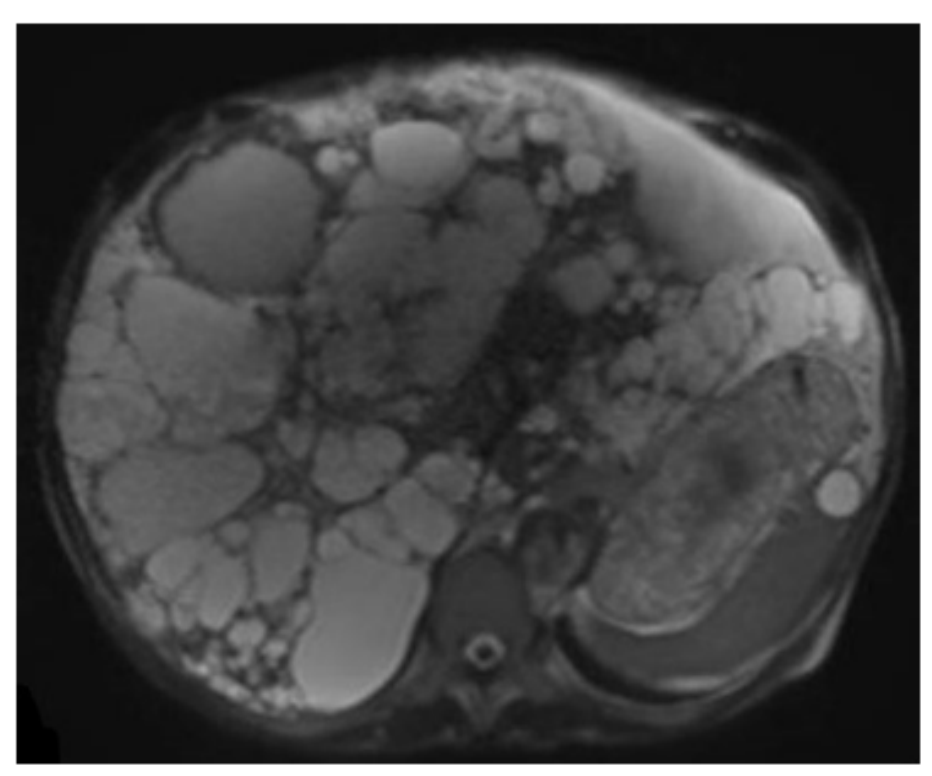

(MRI-T2WI)

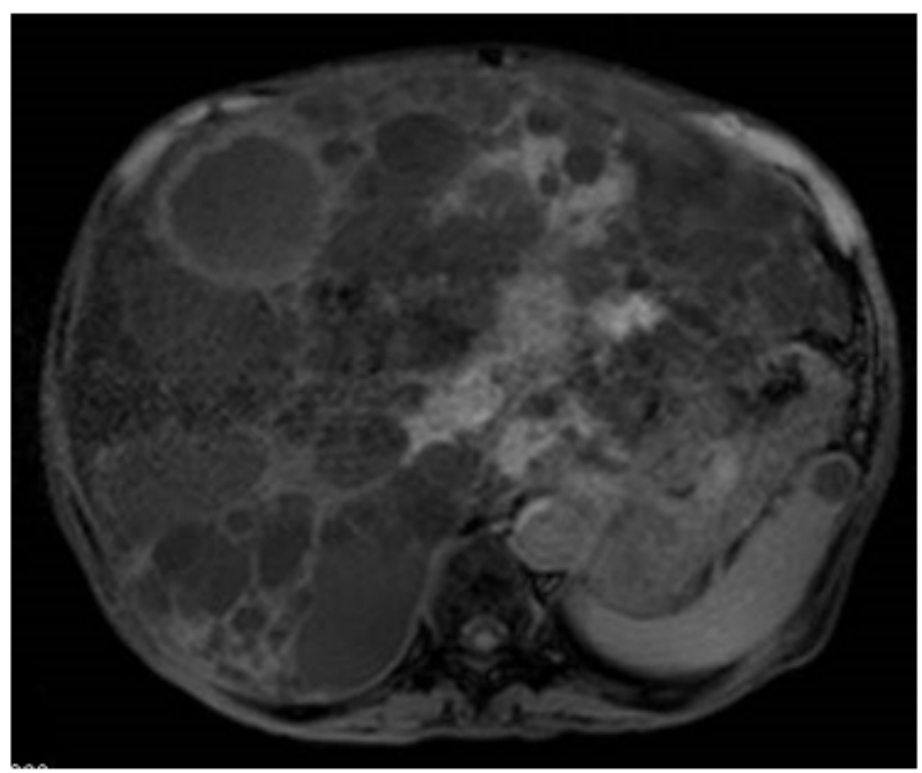

(MRI-T1WI)

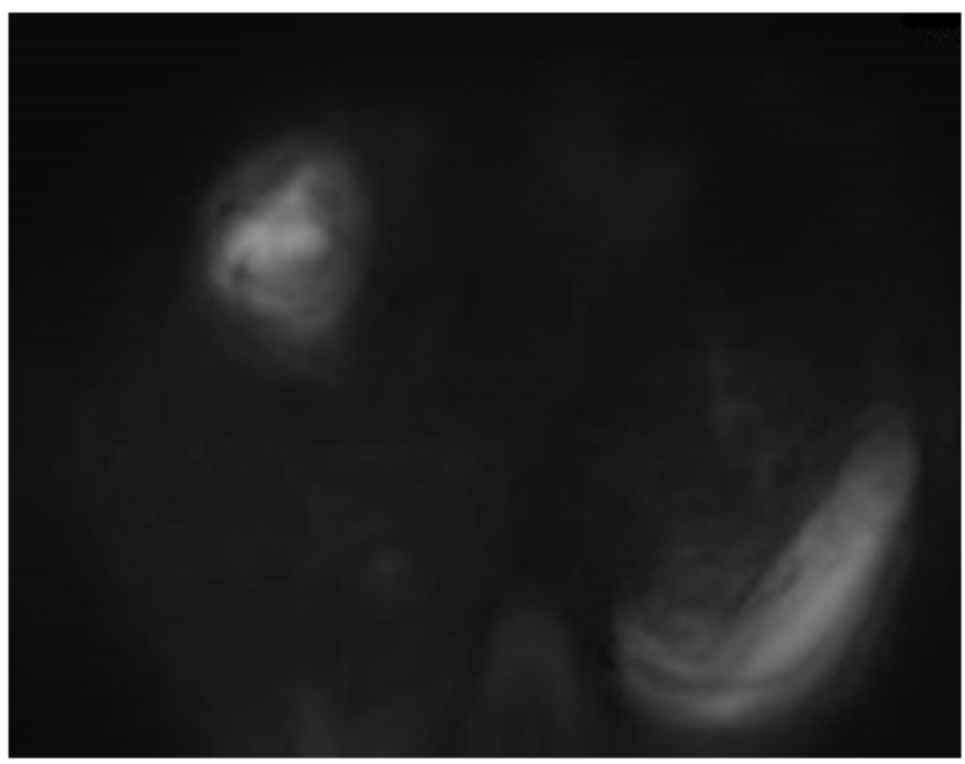

(MRI-DWI)

Figure 3

CT and MRI findings ( $T 1 \mathrm{WI}, \mathrm{T} 2 \mathrm{WI}$, and $\mathrm{DWI})$ in Case 2 . The infected hepatic cyst shows slightly higher density than normal cyst on CT. The infected renal cyst shows a higher intensity on DWI and T1WI than normal cysts, while it has a lower intensity on T2WI. Cyst wall thickening is seen on all images of MRI. 


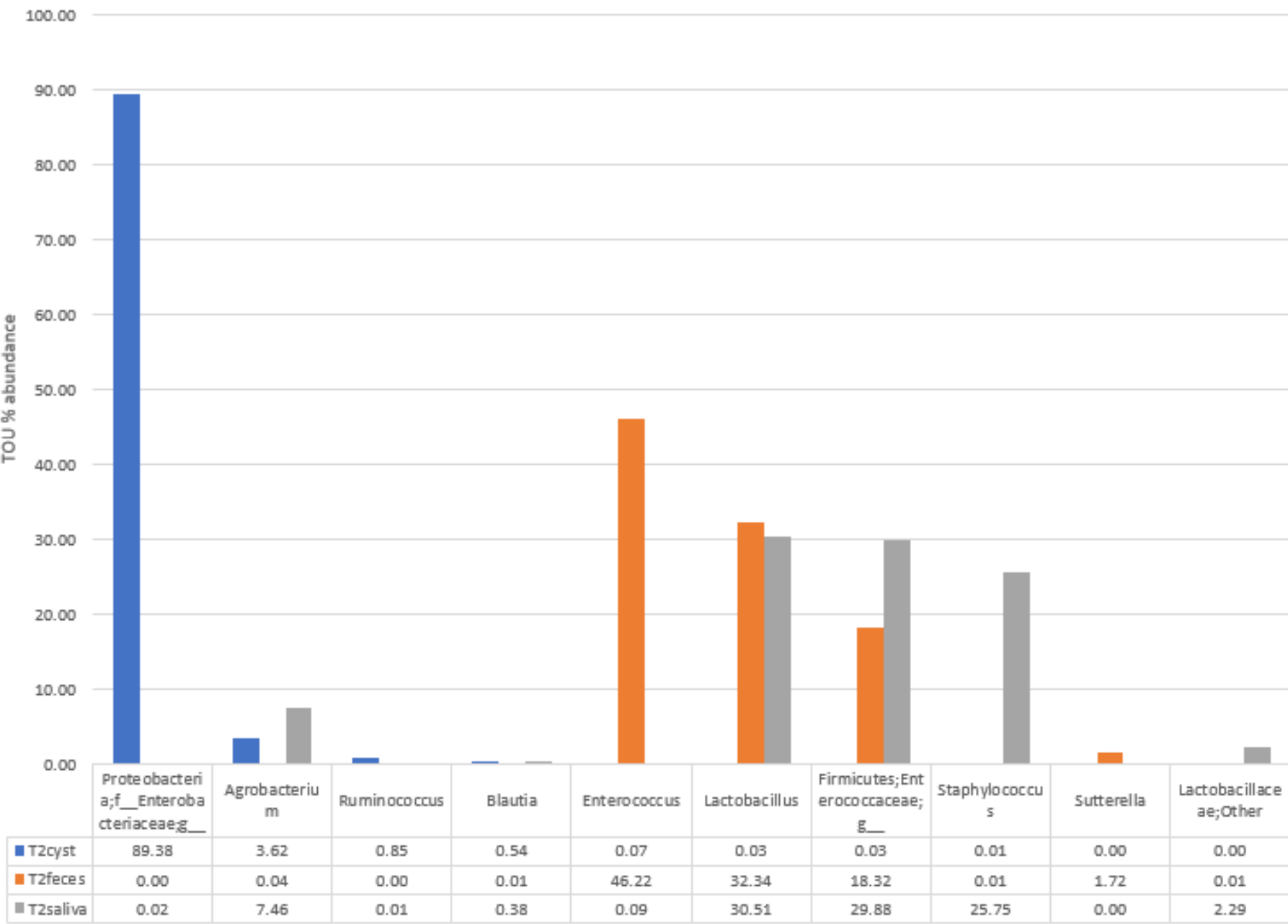

\section{Figure 4}

Top 10 most abundant genera in infected cyst of Case 2 is presented compared to other categories.

\section{Supplementary Files}

This is a list of supplementary files associated with this preprint. Click to download.

- Additional1.doc

- Additionalfile2.xlsx

- Additionalfile3.xlsx 